\title{
22. CHEMISTRY OF WATERS SAMPLED FROM BASALTIC BASEMENT IN DEEP SEA DRILLING PROJECT HOLES 501, 504B, AND 505B'
}

\author{
M. J. Mottl, Woods Hole Oceanographic Institution, Woods Hole, Massachusetts \\ R. N. Anderson, Lamont-Doherty Geological Observatory, Columbia University, Palisades, New York \\ W. J. Jenkins, Woods Hole Oceanographic Institution, Woods Hole, Massachusetts \\ and \\ J. R. Lawrence, Lamont-Doherty Geological Observatory, Columbia University, Palisades, New York
}

\begin{abstract}
The first attempts to sample formation waters from basaltic basement in the oceanic crust were made at Sites 501, 504, and 505 of the Deep Sea Drilling Project. Two methods were used. In the first, the water that occupied the hole was sampled some time after pumping had stopped. In the second, water from both the hole and the surrounding rocks was sampled by sealing off a 3-meter section at the bottom of the hole and opening a large-volume sampler, thereby creating negative pressure. Neither method produced a sample that contained an appreciable and unambiguous component of true formation water, although the samples generally showed large compositional differences from seawater. Samples from Holes 501 and 505B were mainly mixtures of the surface seawater used as drilling fluid and pore water from sediment that fell down the hole. Samples from Hole 504B contained a large fraction of seawater that displayed large chemical changes due to reaction with basement basalts. Tritium analyses revealed the samples to be surface seawater that had been pumped into the formation a few days earlier and had reacted rapidly with basalt at the in situ temperature of $80^{\circ} \mathrm{C}$. The solutions had gained $\mathrm{Ca}$ and lost $\mathrm{Mg}$ on a mole-for-mole basis, lost $\mathrm{K}$ and possibly $\mathrm{SO}_{4}$, and gained $\mathrm{Si}$. The $\mathrm{Si} / \mathrm{Ca}$ ratio increased with depth. These results are consistent with those of laboratory experiments in which seawater reacted with basalt at $70^{\circ} \mathrm{C}$ and indicate that at $80^{\circ} \mathrm{C}$ in situ reaction rates in the crust are sufficiently rapid to produce large changes in solution chemistry almost instantaneously. The absence of an ${ }^{18} \mathrm{O}$ shift in the solutions indicates that the amount of rock that reacted with the solution during its brief residence in the crust was negligible.
\end{abstract}

\section{INTRODUCTION}

The convectively driven circulation of seawater through basaltic basement is probably a ubiquitous process in young oceanic crust (e.g. Lister, 1980), and there is evidence that it may persist in older crust up to $10^{8}$ years in age (e.g., Anderson et al., 1977). Much of this heated seawater eventually exits the seafloor as warm or hot springs, and because it reacts with crustal rocks it is responsible for transferring chemical species as well as heat between the crust and the oceans. The direction and magnitude of the chemical flux depends in part on the composition of the solutions produced when seawater reacts with basalt over a wide range of temperatures. Much is already known about the composition of such solutions produced at high temperatures $\left(200-500^{\circ} \mathrm{C}\right)$, both from experimental studies (e.g., Mottl and Holland, 1978) and from the direct sampling of $350^{\circ} \mathrm{C}$ hot springs along the axis of the East Pacific Rise (Edmond et al., 1982). Less is known about solutions produced at the lower temperatures more typical of circulation through mid-ocean ridge flanks, because warm springs there are more difficult to locate and sample and because the slower reaction kinetics make application of the experimental results more dubious, especially if the temperatures are below $100^{\circ} \mathrm{C}$ (Seyfried and Bischoff, 1979).

\footnotetext{
${ }^{1}$ Cann, J. R., Langseth, M. G., Honnorez, J., Von Herzen, R. P., White, S. M., et al., Init. Repts. DSDP, 69: Washington (U.S. Govt. Printing Office).
}

The first attempts to sample formation waters from basaltic basement in the oceanic crust and to determine their composition directly were made on the southern flank of the Costa Rica Rift, at Sites 501, 504, and 505 of DSDP Legs 68, 69, and 70 (Fig. 1). A complete list of the water samples obtained is given in Table 1. Because of the problems associated with sampling, none of the samples consists of pure formation water. In fact, it is difficult to prove that any of them contains any true formation water, although they contain a sizable proportion of seawater that has reacted with basement basalts.

\section{SAMPLING METHODS}

Two approaches were followed to obtain basement formation water. The first was a passive one in which the water sampled was simply that occupying the drill hole at the time and depth of sampling. A water sampler (either the Gearhart-Owen or Barnes tool) with a valve operated remotely or by timer was lowered into the basement section of the hole, and the valve was opened for a brief period at some depth. The water so obtained is ordinarily mainly drilling fluid, usually surface seawater, which is pumped down the pipe in large quantities during drilling to carry the cuttings up and out of the hole. The water in the hole may also be mainly bottom seawater, as was the case for the first two Leg 70 samples (Table 1). For the water occupying the hole to contain some fraction of formation water, convective exchange must occur between the water in the hole and that occupying the interstices of the surrounding rocks, after the pumping of drilling fluid has ceased. Diffusive exchange of chemical species between the water in the hole and that in the rocks may also occur, as may reaction between the water in the hole and the wall rocks. The relative importance of convection, diffusion, and reaction in determining the composition of the sample obtained depends on the rate and pattern of flow through the hole and the surrounding rock, the temperature-dependent rates of diffusion and reaction, and the length of time since the pumping of drilling fluid through the hole has stopped. 


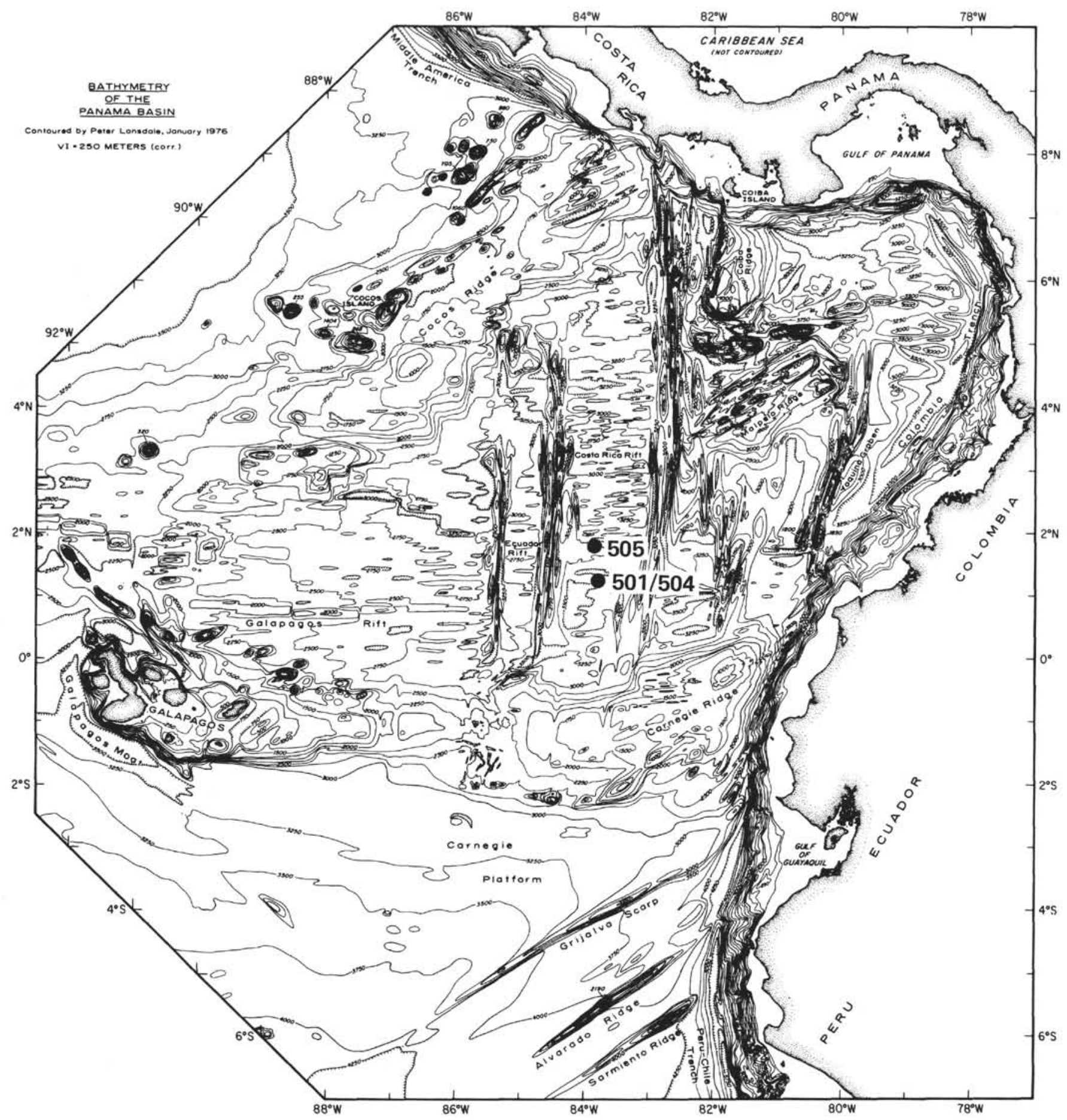

Figure 1. Location of Sites 501, 504, and 505 in the Panama Basin south of the Costa Rica Rift. Bathymetry from Lonsdale and Klitgord (1978). Contour interval is $\mathbf{2 5 0}$ meters.

The second method of water sampling is to use the Lynes retrievable formation tester packer (see Anderson and Zoback, this volume) in conjunction with a large-volume (51 l) sampler to collect a mixture of water from the hole with interstitial water from the rocks. When the packer is inflated near the bottom of the hole, the volume of the lower 3 meters of the hole sealed off is similar to that of the sampler itself, so that a sizable pressure drop ( 310 bars for Hole 504B) occurs when the sampler is opened. The reduction in pressure draws interstitial water from the rocks. The packer sampler consists of six stacked 8 -foot sections of pipe that can be separated by one-way spring-loaded valves that segregate the sample into sequential aliquots as it enters. A single sampling episode thus produces several aliquots from approximately the same depth, which represent mixtures of drill hole water and interstitial water in different proportions. The first solution to enter consists mostly of drill hole water and resides in the uppermost chamber, whereas the last solution to enter contains the highest proportion of pore solution and resides in the lowest chamber, with intermediate mixtures between.

Details of the sampling operations in the various holes using both methods may be found in the appendix. 
Table 1. Water samples collected from basaltic basement.

\begin{tabular}{|c|c|c|c|c|c|c|c|c|c|c|c|c|}
\hline \multirow[b]{2}{*}{ Leg } & \multirow[b]{2}{*}{ Hole } & \multirow[b]{2}{*}{ Sampler $^{\mathrm{a}}$} & \multirow[b]{2}{*}{$\begin{array}{l}\text { Number of } \\
\text { Aliquots }\end{array}$} & \multirow[b]{2}{*}{$\begin{array}{c}\text { Total } \\
\text { Volume (l) }\end{array}$} & \multirow{2}{*}{$\begin{array}{l}\text { Sub-Basement } \\
\text { Depth } \\
\text { (m) }\end{array}$} & \multirow[b]{2}{*}{$\begin{array}{l}\text { Depth below } \\
\text { Seafloor (m) }\end{array}$} & \multirow{2}{*}{$\begin{array}{c}\text { Measured } \\
\text { Temperature } \\
\left({ }^{\circ} \mathrm{C}\right)\end{array}$} & \multirow{2}{*}{$\begin{array}{l}\text { Conductive } \\
\text { Temperature } \\
\left({ }^{\circ} \mathrm{C}\right)\end{array}$} & \multicolumn{4}{|c|}{ Degree of Contamination from- } \\
\hline & & & & & & & & & $\begin{array}{l}\text { Surface } \\
\text { Seawater }\end{array}$ & $\begin{array}{c}\text { Bottom } \\
\text { Seawater }\end{array}$ & $\begin{array}{c}\text { Sediment } \\
\text { Pore Water }\end{array}$ & $\begin{array}{c}\text { Drilling } \\
\text { Mud Slurry }\end{array}$ \\
\hline \multirow[t]{2}{*}{68} & 501 & Packer & 2 & 51 & 19 & 283 & - & 61 & $\mathrm{H}^{\mathrm{c}}$ & - & VL? & - \\
\hline & & G-O & 1 & 0.1 & 48 & 312 & 41.5 & 63 & $\mathrm{H}$ & - & $\mathrm{H}$ & M \\
\hline \multirow[t]{2}{*}{69} & 504B & G-O & 1 & 2.2 & 194 & 468.5 & 69 & 80 & $\mathrm{H}$ & - & - & L \\
\hline & & Packer & 7 & 51 & 211.5 & 486 & - & 81.5 & $\mathrm{H}$ & - & - & VL \\
\hline \multirow[t]{5}{*}{70} & 504B & Barnes 173 & 1 & 0.06 & 80 & 355 & 8.5 & 68.5 & L & VH & - & - \\
\hline & & Barnes 174 & 1 & 0.06 & 185 & 460 & 76 & 78.5 & & $\mathrm{H}$ & - & - \\
\hline & & Barnes 175 & 1 & 0.06 & 365 & 640 & 76 & 98 & $\mathrm{H}$ & - & - & VL \\
\hline & & Barnes 194 & 1 & 0.06 & 440 & 715 & - & 106.5 & $\mathrm{H}$ & - & - & L \\
\hline & & G-O & 1 & 1 & $\sim 560$ & $\sim 835$ & 111 & 120 & $\mathbf{H}$ & - & - & VH \\
\hline 69 & $505 B$ & G-O & 1 & 0.11 & $23(8)$ & 159 (144) & $\sim 3$ & - & $\mathrm{H}$ & - & $\mathrm{H}$ & - \\
\hline
\end{tabular}

a Packer denotes Lynes packer; G-O, Gearhart-Owen wireline tool; Barnes, in situ water sampler.

$\mathrm{b}$ Measured temperature is the in situ temperature of the sample when collected. Conductive temperature is the in situ temperature prior to disturbance by drilling, as estimated from temperature and conductivity measurements in the sediment section for Hole 501 and from the temperature logs in basement for Hole 504B.

${ }^{\mathrm{c}} \mathrm{H}$ denotes heavy; $\mathrm{VL}$, very light; $\mathrm{M}$, moderate; $\mathrm{L}$, light; $\mathrm{VH}$, very heavy.

\section{CONTAMINATION}

Besides the abundant admixture of surface or bottom seawater in all of the basement water samples, three other sources of contamination have probably affected some of the samples: (1) the barite-bentonite freshwater slurries used routinely to flush the holes after drilling, (2) the sediment with associated pore water that caved in and fell into the basement section of the hole from above, and (3) the drilling and sampling apparatus itself, which consists mainly of rusted steel pipe and has various greases and other lubricants associated with it. Estimates of the probable abundance of the various contaminants in the samples are given in Table 1; the estimates are based on the chemistry of the samples themselves, with the sequence of drilling operations providing supporting evidence.

Attempts were made in every case to flush the bentonite slurries from the hole with surface seawater prior to sampling, with mixed success. Although in most cases the hole itself was adequately flushed, it is doubtful that any mud that might have been pumped into the interstices of the surrounding rock could ever be completely flushed out. Flushing with voluminous quantities of surface seawater, moreover, obviously diminishes the chances of recovering a sizable fraction of formation water.

As for caved-in sediment, it is no coincidence that the basement water samples from the two uncased holes (Holes 501 and 505B) show clear evidence of contamination from sediment and sediment pore water, whereas such evidence is lacking in the samples from Hole 504B, where the entire sediment section was cased (lined) with steel pipe cemented into basement at its bottom end. Casing the sediment section may be a prerequisite for obtaining reliable samples of basement formation water.

Contamination from the drilling and sampling apparatus can occur either within the hole, so that the water is already contaminated when it is sampled, or within the sampler itself after sampling. One demonstrated source of contamination is the grease used to lubricate the threads and moving parts of the sampler. Seawater put in contact with either "green grease" (Aqua-Lube, Allube Div., Far Best Corp., Los Angeles, Calif.) or “yellow grease"' (No. 630-2 Multipurpose Grease, Lubri- plate Div., Fiske Bros. Refining Co., Newark, N.J.) at $25^{\circ} \mathrm{C}$ was found to pick up Li readily, reaching concentrations of several hundred $\mu \mathrm{M}$. The other analyzed chemical species were unaffected. "Pipe dope" (Mr. B lead-base tool joint compound, Bestalife Corp., Dallas, Tex.) was found not to affect the concentrations of any of the analyzed species.

\section{ANALYTICAL PROCEDURES AND RESULTS}

Unfiltered aliquots from the larger Leg 69 samples were immediately sealed on deck into 1-gal. glass jugs for the shore-based analysis of tritium. Unfiltered aliquots were also used for the analysis of $U$ and ${ }^{234} \mathrm{U} / 2{ }^{238} \mathrm{U}$ (Bacon, this volume). All other aliquots were filtered through $0.45-\mu \mathrm{m}$ cellulose membrane filters and analyzed in the shipboard laboratory for $\mathrm{pH}$, alkalinity, chlorinity, salinity (refractive index), $\mathrm{Ca}$, and $\mathrm{Mg}$ by using standard titration techniques (Gieskes, 1974). Shore-based analyses were made for $\mathrm{Sr}, \mathrm{Fe}, \mathrm{Mn}, \mathrm{Li}$, and $\mathrm{K}$ by flame atomic absorption spectrophotometry, $\mathrm{Si}$ and $\mathrm{NH}_{3}$ by colorimetry, $\mathrm{SO}_{4}$ by difference chromatography (Sayles and Mangelsdorf, 1976) corrected for variable chlorinity, and $\delta^{18} \mathrm{O}$ by mass spectrometry. Na was calculated from charge balance. ${ }^{3} \mathrm{H}$ (tritium) was analyzed by stripping the gases, incubating the samples for $1 \mathrm{yr}$., and measuring the ingrowth of ${ }^{3} \mathrm{He}$ due to ${ }^{3} \mathrm{H}$ decay.

The analytical results and uncertainties are as given in Table 2.

\section{DISCUSSION}

\section{Hole 505B}

The G-O sample from Hole 505B yielded values for alkalinity, chlorinity, salinity, $\mathrm{Ca}, \mathrm{Mg}, \mathrm{Mn}$, and $\mathrm{NH}_{3}$ that are between those for surface seawater and the most altered pore waters from the overlying sediments. The mud separated from the sample by centrifuge contains Pleistocene diatoms (C. Sancetta, pers. comm., 1979). The Ca concentration is lower than that in seawater, whereas alkalinity and $\mathrm{Mg}$ are higher, as is the case for the sediment pore waters from Hole 505 (Mottl et al., this volume). These trends are the opposite of those that typically result from the reaction of seawater with basalt. Thus, this sample is almost certainly a mixture of surface seawater with pore water from sediments that 
Table 2. Composition of surface seawaters and water samples collected from basement on Legs 68 to 70 .

\begin{tabular}{|c|c|c|c|c|c|c|c|c|c|c|c|c|c|c|c|c|c|c|c|c|}
\hline Hole & Sample $^{\mathrm{a}}$ & $\begin{array}{c}\mathrm{pH} \\
\text { at } \\
25^{\circ} \mathrm{C}\end{array}$ & $\begin{array}{l}\text { Alkalinity } \\
\text { (meq/l) }\end{array}$ & $\begin{array}{c}\text { Chlorinity } \\
(\mathrm{mM})^{b}\end{array}$ & $\begin{array}{c}\text { Salinity } \\
(\%)\end{array}$ & $\begin{array}{c}\mathrm{Ca} \\
(\mathrm{mM})\end{array}$ & $\underset{(\mathrm{mM})}{\mathrm{Mg}}$ & $\underset{(\mu \mathrm{M})^{\mathrm{c}}}{\mathrm{Sr}}$ & $\underset{(\mu \mathrm{M})^{\mathrm{d}}}{\mathrm{Sr}}$ & $\begin{array}{c}\mathrm{Fe} \\
(\mu \mathrm{M})\end{array}$ & $\underset{(\mu \mathrm{Mn})}{\mathrm{Mn}}$ & $\underset{(\mu \mathrm{M})}{\mathrm{Li}}$ & $\underset{(\mathrm{mM})^{\mathrm{c}}}{\mathrm{K}}$ & $\underset{(\mathrm{mM})^{\mathrm{d}}}{\mathrm{K}}$ & $\underset{(\mathrm{mM})}{\mathrm{Na}}$ & $\underset{(\mathrm{mM})}{\mathrm{SO}_{4}}$ & $\begin{array}{l}\mathrm{NH}_{3} \\
(\mu \mathrm{M})\end{array}$ & $\underset{(\mu \mathrm{M})}{\mathrm{Si}}$ & $\begin{array}{l}\delta^{18} \mathrm{O} \\
(\%)\end{array}$ & $\begin{array}{c}{ }^{3} \mathrm{H} \\
\text { (T.U.) }\end{array}$ \\
\hline \multirow[t]{4}{*}{501} & SSW & 8.07 & 2.42 & 525.0 & 33.3 & 9.61 & 50.81 & 85.6 & - & - & - & 24.6 & 10.07 & - & - & - & $<10$ & 0.5 & - & - \\
\hline & P-8 & 7.13 & 2.64 & 527.6 & 33.0 & 10.30 & 50.09 & 82.5 & - & - & 21.8 & 25.2 & 9.93 & - & - & - & 81 & 17.2 & - & - \\
\hline & P-9 & 7.78 & 2.20 & 528.4 & 33.3 & 9.94 & 50.28 & 83.1 & - & - & 12.1 & 25.2 & 10.04 & - & - & - & 72 & 18.4 & - & - \\
\hline & GO-1 & - & - & - & 32.7 & 33.49 & 21.40 & - & - & - & 13.0 & - & - & - & - & - & 218 & - & -0.8 & - \\
\hline \multirow[t]{18}{*}{$504 \mathrm{~B}$} & SSW & 7.98 & 2.34 & 538.9 & 33.8 & 10.29 & 52.03 & 83.0 & 87.3 & $<1.7$ & $<1.9$ & 25.3 & 9.89 & 9.87 & 461.9 & 27.81 & $<10$ & 1.4 & 0.1 & 2.46 \\
\hline & PS-5 & 7.42 & 1.97 & 538.2 & 33.6 & 11.26 & 50.46 & 80.4 & 87.1 & $<1.7$ & 26.9 & 39.8 & 9.74 & 9.76 & 462.2 & 27.87 & $<10$ & 43.5 & 0.2 & 2.52 \\
\hline & PS-4 & - & - & 539.1 & 33.7 & 11.54 & 50.48 & 81.7 & 87.2 & 0.5 & 26.2 & 38.1 & 9.78 & - & 462.6 & 27.92 & $<10$ & 46.4 & 0.0 & 2.55 \\
\hline & PS-3 & 7,48 & 1.99 & 540.5 & 33.8 & 12.06 & 49.90 & 82.9 & & 0.6 & 26.2 & 36.6 & 9.63 & - & 464.2 & 27.88 & $<10$ & 66.0 & 0.0 & - \\
\hline & PS-2 & - & - & 539.8 & 33.7 & 12.91 & 49.04 & 84.5 & 88.1 & 0.6 & 28.6 & 36.1 & 9.69 & 9.85 & 463.2 & 27.81 & $<10$ & 83.2 & 0.1 & 2.67 \\
\hline & PS-1 & 7.36 & 1.81 & 547.0 & 33.8 & 17.51 & 44.38 & 85.5 & 87.9 & 11.2 & 23.5 & 41.3 & 9.52 & 9.43 & 469.7 & 27.39 & $<10$ & 158 & 0.0 & 2.48 \\
\hline & PS-A & 7.74 & $1.6 \mathrm{I}$ & 545.1 & 33.8 & 18.45 & 43.51 & 81.9 & 87.9 & 1.7 & 27.9 & 60.1 & 9.62 & 9.51 & - & - & $<10$ & 140 & 0.2 & - \\
\hline & PS-S ${ }^{\mathrm{e}}$ & - & - & 546.1 & 36.4 & 21.81 & 42.98 & - & - & - & - & 882 & 9.77 & - & - & - & - & 70.5 & 1.1 & - \\
\hline & GO-2 & 6.55 & $\left\{\begin{array}{l}2.19 \\
1.87\end{array}\right.$ & 550.5 & 34.6 & 14.69 & 47.23 & 86.0 & 90.0 & $>200$ & 28.2 & 31.9 & 9.77 & 10.08 & 473.4 & 27.56 & $<10$ & 177 & - & 2.51 \\
\hline & 173, prime & - & - & 549.8 & 34.4 & 10.54 & 53.11 & - & - & - & - & - & - & - & - & - & - & 134 & - & - \\
\hline & 173 , overflow $f$ & - & - & 554.7 & - & 10.58 & 53.74 & - & - & - & - & 28.0 & - & - & - & 27.8 & - & - & - & - \\
\hline & $\begin{array}{l}174 \text {, prime } \\
\text {. }\end{array}$ & - & - & 552.7 & - & 15.66 & 48.94 & - & - & - & - & - & - & - & - & - & - & 239 & - & - \\
\hline & 174 , overflow $f$ & - & - & 554.7 & - & 15.30 & 48.98 & - & - & - & - & 31.1 & - & - & - & 28.0 & - & - & - & - \\
\hline & 175, prime & - & - & 526.4 & 33.5 & 11.52 & 50.01 & - & - & - & - & - & - & - & - & - & - & 78 & - & - \\
\hline & 175, overflow8 & - & - & 392.4 & 25.5 & 14.22 & 47.66 & - & - & - & - & 26.9 & - & - & - & 26.9 & & 225 & - & - \\
\hline & 194, prime & - & - & 517.2 & 33.3 & 13.35 & 47.07 & - & - & - & - & - & - & - & - & - & - & 586 & - & - \\
\hline & 194, overflowg & - & - & 383.7 & 24.2 & 13.25 & 47.95 & - & - & - & - & 26.9 & - & - & - & 26.5 & - & 479 & - & - \\
\hline & GO-1 & - & - & 536.5 & 34.1 & 24.35 & 44.33 & - & - & - & - & - & - & - & - & - & - & 970 & - & - \\
\hline \multirow[t]{2}{*}{$505 \mathrm{~B}$} & SSW & 8.03 & - & 528.4 & 33.1 & 10.44 & 51.55 & 86.0 & - & $<1.7$ & $<1.9$ & 24.1 & 10.07 & - & - & - & $<10$ & - & - & - \\
\hline & GO-1 & 8.32 & 3.69 & 545.4 & 33.7 & 8.48 & 52.52 & - & - & - & 18.4 & 33.5 & - & - & - & - & 109 & - & - & - \\
\hline \multicolumn{2}{|c|}{ Uncertainty $(\%)$ : } & - & 10 & 1 & 0.5 & 2 & 2 & 2 & 0.5 & 2 & 2 & 2 & 2 & 0.5 & - & 0.15 & 10 & 3 & - & 1.5 \\
\hline
\end{tabular}

fell down the hole from far up in the section. There is no evidence that it contains any formation water. The high concentrations of $\mathrm{Li}$, which are higher than in any of the sediment pore water samples, almost certainly resulted from contamination by the "green grease" (Aqua-Lube) used on the moving parts of the sampler.

\section{Hole 501}

As in Hole 505B, the G-O sample from Hole 501 was muddy and yielded values for $\mathrm{Ca}, \mathrm{Mg}, \mathrm{Mn}$, and $\mathrm{NH}_{3}$ in the same range as those from the pore waters in the overlying sediment. The moderate depletion in $\delta^{18} \mathrm{O}$ is likewise similar to that in the sediment pore waters, which ranges from 0 to $-4.5 \%$ (Mottl et al., this volume). The salinity of the sample is lower than that of surface seawater, which is lower than that of the sediment pore waters. This suggests that the sample is slightly contaminated with the freshwater drilling mud slurry used to clean the hole. Some of the Mn may result from contamination from the steel sampler barrel. The sample is probably mainly pore water from sediment that is known to have fallen down the hole (see Appendix) mixed with surface seawater.

The packer sample aliquots have concentrations of $\mathrm{Ca}$ a few percent higher and $\mathrm{Mg}$ and $\mathrm{Sr}$ up to a few percent lower than those in surface seawater. The concentrations of $\mathrm{Li}$ and $\mathrm{K}$ are indistinguishable from those in surface seawater, whereas $\mathrm{Mn}, \mathrm{NH}_{3}$, and $\mathrm{Si}$ are much higher. The sample can be modelled adequately as a mixture of surface seawater with 1 to $2 \%$ sediment pore water, except that $\mathrm{Sr}$ is too low and $\mathrm{Mn}$ and $\mathrm{NH}_{3}$ are too high. The high $\mathrm{Mn}$ is probably due to contamination from the steel sampler barrels, and the high $\mathrm{NH}_{3}$ may be a greatly diluted signal from the $\mathrm{NH}_{4} \mathrm{Cl}$ "spike" pumped down in the drilling fluid (see Appendix). The low $\mathrm{Sr}$ concentration is difficult to explain by this model, however: the $\mathrm{Sr} / \mathrm{Ca}$ molar ratio ranges from 0.0087 to 0.0176 in the sediment pore waters from this hole, and it is 0.0089 in the surface seawater, whereas it is only 0.0081 and 0.0084 in the packer aliquots. The low $\mathrm{Sr}$ concentration may indicate that the packer aliquots are mixtures of surface seawater with a minute fraction of basalt formation water, which would then have to exhibit chemical changes similar to those seen in the sediment pore waters for $\mathrm{Ca}, \mathrm{Mg}, \mathrm{Li}, \mathrm{K}$, and $\mathrm{Si}$.

This possibility is further supported by the high $\mathrm{CO}_{2}$ content of the gas removed through the needle valve at the top of the sampler. Whereas the sampler was full of air prior to sampling, this gas was enriched in $\mathrm{CO}_{2}$ fivefold relative to air, as determined by shipboard gas chromatography. This suggests that the formation water may be $\mathrm{CO}_{2}$ rich. Neither the gas nor solution aliquots from this or any other sample had any trace of $\mathrm{H}_{2} \mathrm{~S}$ odor.

\section{Hole 504B}

With the exception of the Barnes sample IW-173, which is nearly identical to ocean bottom water, all of the samples from Hole 504B show large chemical changes relative to seawater. These changes, moreover, cannot be due to the admixture of sediment pore water, because of (1) the absence of detectable $\mathrm{NH}_{3}$ in the samples (the $\mathrm{NH}_{3}$ concentration was 0.2 to $1.0 \mathrm{mM}$ in the sediment pore water at this site); (2) the low concentration of $\mathrm{Sr}$ and the low $\mathrm{Sr} / \mathrm{Ca}$ ratios $(0.0044$ to 0.0077$)$ (the $\mathrm{Sr} / \mathrm{Ca}$ ratio in the sediment pore water was 0.0087 to 0.0205 ); (3) the high ratio of ${ }^{87} \mathrm{Sr} /{ }^{86} \mathrm{Sr}$ to $\mathrm{Ca}$ (that in the sediment pore water is given in figure 7 of the chapter by Hart and Mottl, this volume); (4) the absence of shift in the 
$\delta^{18} \mathrm{O}$ values (the values for the sediment pore water show a negative shift to $-4.5 \%$ ) and (5) the absence of pelagic sediment in the sample aliquots. Suspended material filtered from the samples consists of powdered basalt and rust from the drill pipe and sampler. These findings are consistent with the fact that the entire sediment section was lined with casing before the basement in this hole was drilled.

With the exception of the GO-1 sample from Leg 70, it is equally unlikely that these chemical changes have resulted from contamination with the barite-bentonite freshwater muds used to flush the hole. Hart and Mottl (this volume) showed that whereas the $\mathrm{Rb}, \mathrm{Cs}$, and $\mathrm{Ba}$ data may be seriously affected by contamination from this source, the $\mathrm{K}, \mathrm{Sr}$, and $\mathrm{Sr}$ isotope data are not. For the same reasons, the $\mathrm{Ca}$ and $\mathrm{Mg}$ data are not significantly affected: the ratio of $\mathrm{Ca}$ to $\mathrm{Cs}$, for example, in the water samples is an order of magnitude greater than that in clays (but only one-third that in basalts). If it is assumed that $\mathrm{Cs}$ is leached preferentially to $\mathrm{Ca}$, the small increase in Cs observed in the waters limits the amount of bentonite-derived $\mathrm{Ca}$ to a small fraction of the $\mathrm{Ca}$ added to the water.

The only possible source for most of the chemical changes observed in basement waters from this hole, therefore, is reaction with the basement basalts.

The composition of the packer aliquots in the PS series in Table 2 varies systematically with the position of the aliquot in the sampler for alkalinity, $\mathrm{Ca}$, and $\mathrm{Mg}$ and approximately so for chlorinity, $\mathrm{Sr}, \mathrm{K}, \mathrm{SO}_{4}$, and $\mathrm{Si}$. The data of Hart and Mottl (this volume) show that this is also the case for ${ }^{87} \mathrm{Sr} /{ }^{86} \mathrm{Sr}, \mathrm{Rb}, \mathrm{Cs}$, and $\mathrm{Ba}$. The variation is such that the first aliquot to enter the sampler (PS-5) most closely resembles surface seawater, as is to be expected, since the hole was flushed with surface seawater for $1 \mathrm{hr}$. immediately prior to sampling. The aliquots that differ most from surface seawater are those that entered last and were isolated in the lower part of the sampler by one-way valves. The lower aliquots thus contain progressively larger proportions of the water drawn from the pores in the rocks surrounding the hole. This interstitial water is mixed with surface seawater that filled the hole prior to sampling.

When plotted against one another, therefore, chemical species that behave conservatively during mixing should fall on a mixing line between surface seawater and interstitial water from the rocks. In the Leg 69 samples this is the case for $\mathrm{Ca}$ versus $\mathrm{Mg}$, alkalinity, chlorinity, and sulfate and approximately for silica (Figs. 2 to 6). It is also true for $\mathrm{K}, \mathrm{Rb}, \mathrm{Cs}, \mathrm{Sr}$, and ${ }^{87} \mathrm{Sr} /{ }^{86} \mathrm{Sr}$ (Hart and Mottl, this volume). The sole exception among the packer aliquots (Fig. 2) is PS-S, a 12-ml sample of water squeezed from the basalt mud that was removed from the sampling port assembly. This sample could have reacted with the solids in the mud or exchanged with the water in the hole as the sampler was brought back to the surface. The Leg 70 samples, which came from the same and greater depths, show the same Ca versus $\mathrm{Mg}$ relationship (not shown). They also reveal that the $\mathrm{Si} / \mathrm{Ca}$ ratio increases with increasing depth (Fig. 6).
It remains to determine the nature and composition of the interstitial water end-member. In the present case, the most helpful chemical species for this purpose is tritium, which is abundant in surface seawater at this site because of its introduction via nuclear weapons testing in the 1950 s and 1960 s. Because tritium was introduced recently and because its half-life is only $12.5 \mathrm{yr}$., it has not penetrated to ocean bottom waters, and it would certainly be absent in true basement formation water. Its concentration in surface seawater pumped down the hole would not be readily altered by reaction with the rocks or sampler, and it can be expected to behave conservatively on mixing. It is thus a perfect tracer for the surface seawater end-member, although it cannot be used to distinguish basement formation water from either bottom seawater or sediment pore water, all of which would be tritium free.

Table 2 shows that, with respect to tritium content, all of the packer aliquots and the G-O sample are indistinguishable from surface seawater. This result is unexpected, in view of the large chemical and $\mathrm{Sr}$-isotope differences between the samples and surface seawater. Nor can these differences be due to the admixture of sediment pore water: in addition to the evidence cited earlier, the tritium data themselves do not allow for more than a negligible fraction of this component. The tritium data are, however, consistent with the absence of a negative shift in $\delta^{18} \mathrm{O}$, which suggests that only a minute quantity of rock has reacted with these solutions at this temperature. Reaction with a small quantity of rock can produce large changes in the cation composition of interstitial waters without affecting their oxygen isotope composition, because the waters contain as much oxygen as the surrounding rocks but only a small fraction of the cations (Lawrence et al., 1975).

The only reasonable interpretation of these data is that the packer aliquots represent mixtures of unreacted surface seawater drawn from the hole with varying amounts of a highly reacted surface seawater drawn from the pores in the rocks surrounding the hole. The reacted surface seawater sampled from the rocks was apparently pumped into the basement formation during earlier operations in the hole. Some of the surface seawater used as drilling fluid or to flush the hole may have leaked into the formation, but the most likely source of the reacted water is the 1000 gal. pumped into basement about 4 days earlier over the same 3-meter interval, when the packer was set at this depth for the second group of pressure-pulse tests (see Appendix). In any case, the surface seawater cannot have been introduced into basement any sooner than $\mathbf{1 6 . 5}$ days prior to sampling with the packer, because that was when the basement of Hole 504B was first penetrated. The sampled interval was first penetrated 6 days before sampling.

In light of these data it is not possible to determine the composition of the interstitial water end-member and thus the extent to which the reaction of the surface seawater progressed during the brief period the water resided in the interstices of the rocks. A minimum estimate of reaction extent is, of course, provided by the 


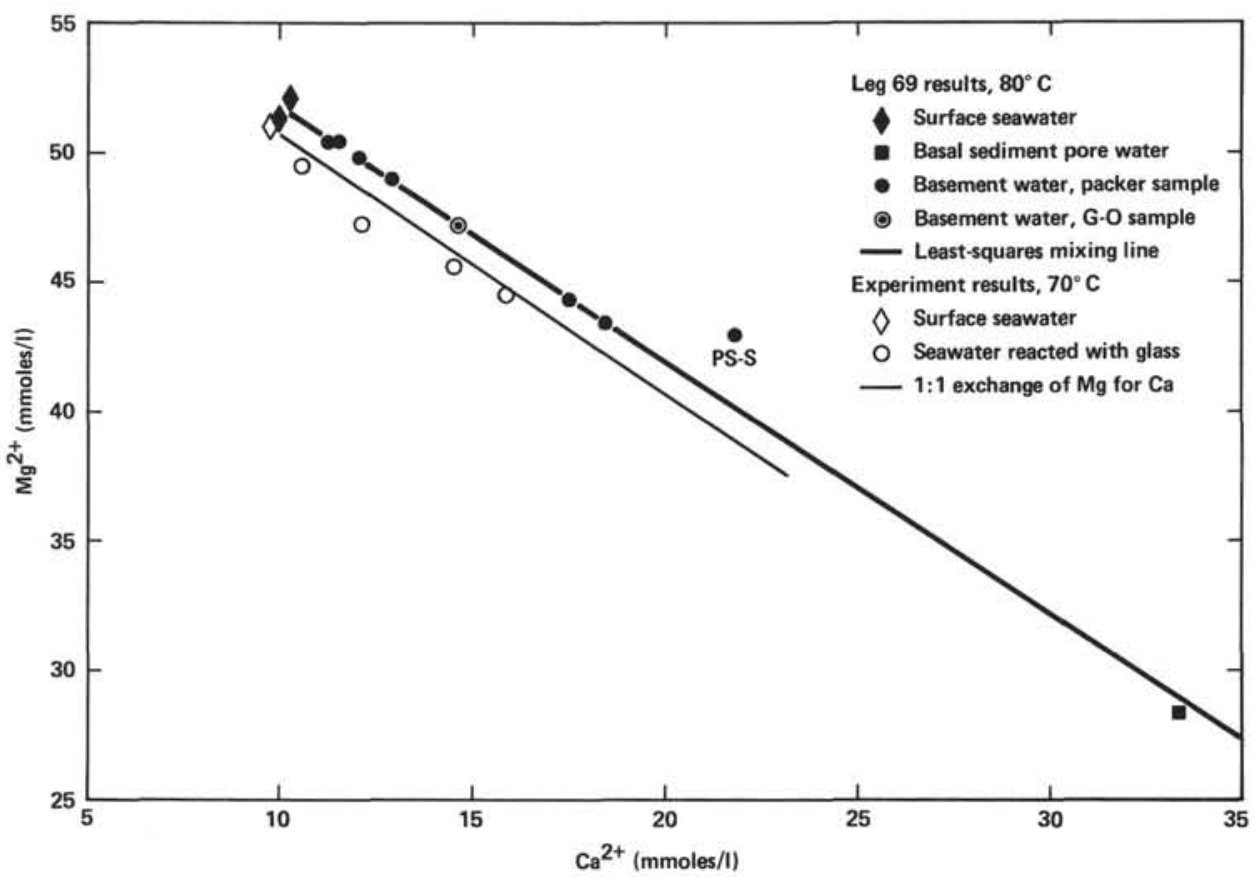

Figure 2. Ca versus $\mathrm{Mg}$ concentration in $80^{\circ} \mathrm{C}$ waters sampled from basement on Leg 69 from Hole 504B. The least-squares mixing line passes through surface seawater and the lowest sediment pore water sample (from $10 \mathrm{~m}$ above basement). Shown for comparison are data from a laboratory experiment in which seawater reacted with basalt glass at $70^{\circ} \mathrm{C}$ (Seyfried and Bischoff, 1979); in that experiment $\mathrm{Mg}$ decreased continuously for 150 days. Lines that represent 1:1 exchange of $\mathrm{Mg}$ for $\mathrm{Ca}$ for seawater of different chlorinity will all parallel the one shown.

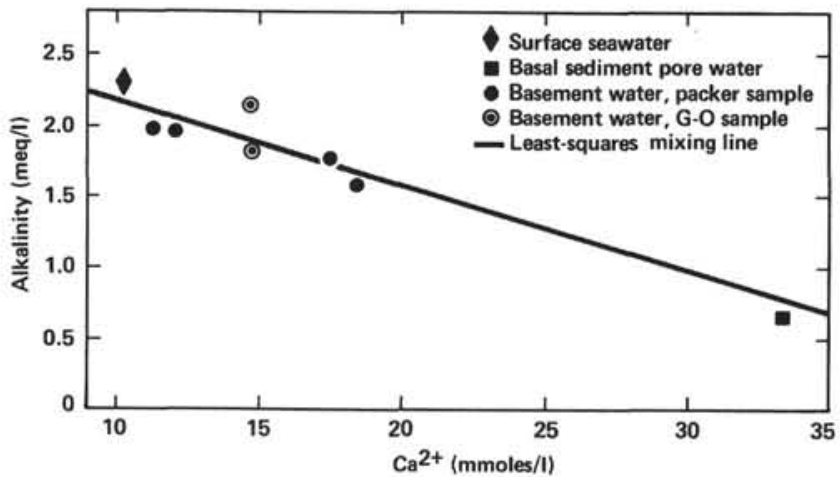

Figure 3. Ca versus alkalinity in the Leg 69 basement water samples from Hole 504B, compared with surface seawater and the lowest sediment pore water sample from the same hole.

most altered aliquot, PS-A, which has a Ca concentration 1.8 times that of surface seawater. The fraction of unreacted surface seawater in this aliquot may be quite large, however, so the extent of the reaction of the solution may be much greater than that shown by PS-A. It is even possible that the surface seawater had largely equilibrated with the secondary minerals at the in situ temperature of $80^{\circ} \mathrm{C}$, although the lack of an ${ }^{18} \mathrm{O}$ shift limits the amount of rock with which the solution can have reacted.

The minimum rate of reaction between seawater and basalt that can be inferred from these data is far more rapid than that observed in the laboratory experiments of Seyfried (1977) and Seyfried and Bischoff (1979) at

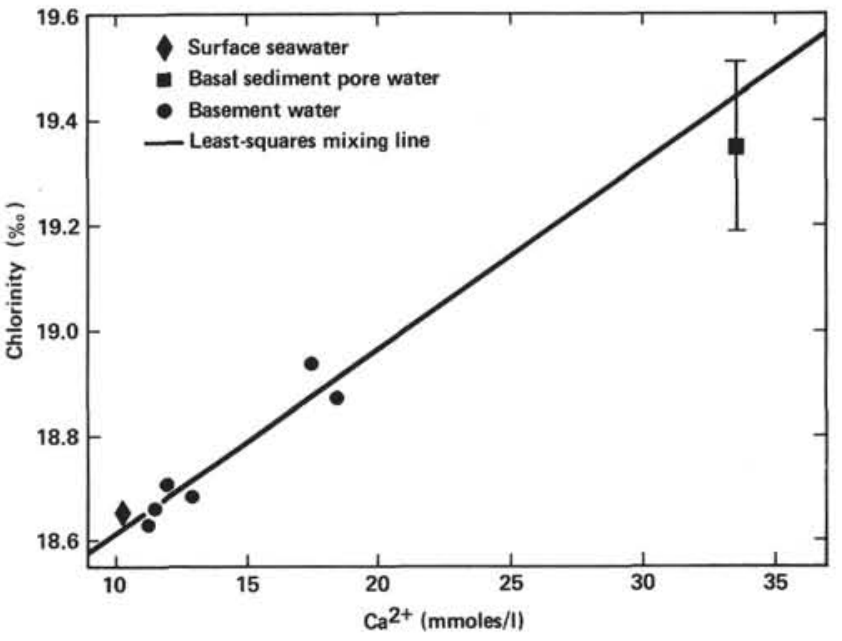

Figure 4. Ca versus chlorinity in the packer samples from Hole 504B, compared with surface seawater and the lowest sediment pore water sample from the same hole.

$70^{\circ} \mathrm{C}$. In their experiments, the reaction of seawater with basalt glass and diabase increased the $\mathrm{Ca}$ concentration in the solution by a factor of only 1.1 after 6 to 8 days, and by 1.7 after 150 to 180 days (glass) and 1.2 after 83 to 143 days (diabase). As in the Hole 504B samples, $\mathrm{K}$ and $\mathrm{Mg}$ decreased, and the $\mathrm{Mg}$ lost from seawater was balanced nearly mole-for-mole by $\mathrm{Ca}$ gained (Fig. 2). The rock in the experiment was ground, and the 43 to $73 \mu \mathrm{m}$ size fraction was used. The mass ratio of rock to seawater was $1: 10$. It is difficult to relate these 


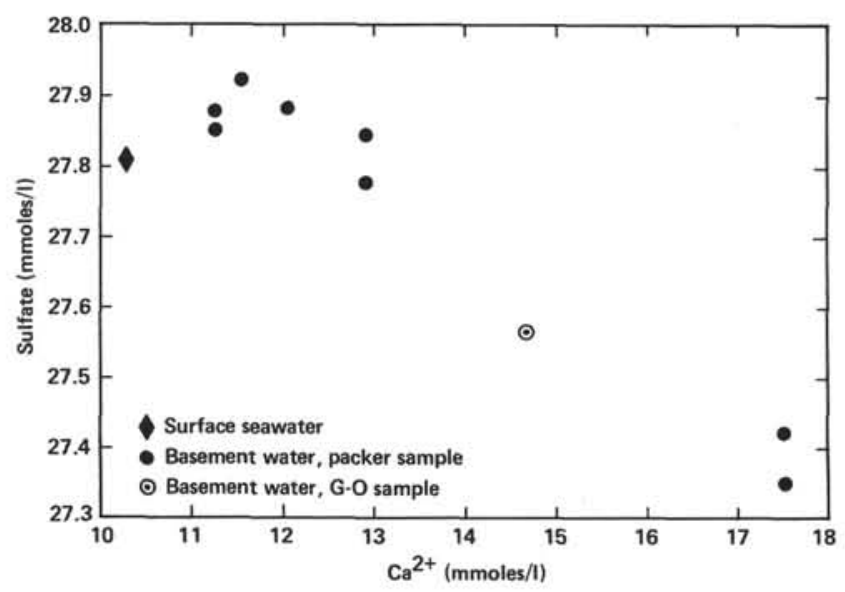

Figure 5. Ca versus sulfate in the Leg 69 basement water samples from Hole 504B taken with the packer and the G-O sampler compared with surface seawater.

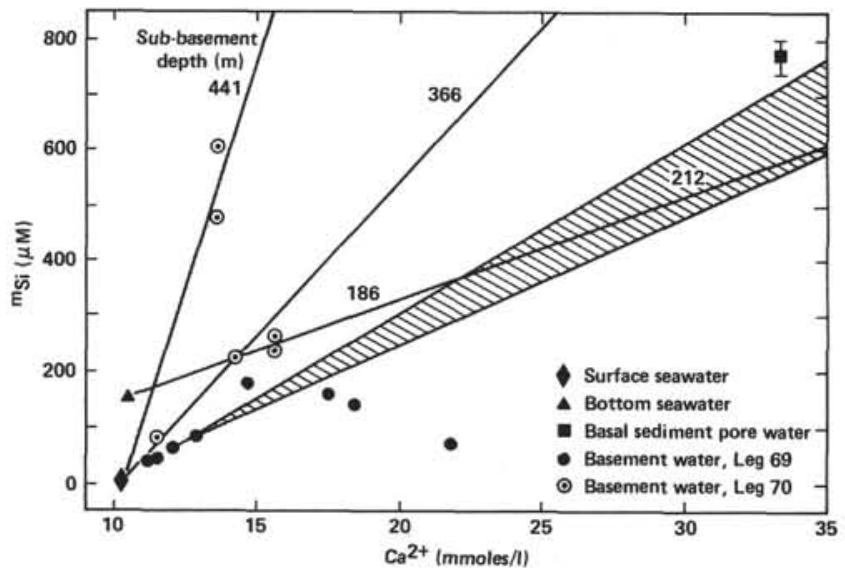

Figure 6. Ca versus $\mathrm{Si}$ in the Leg 69 and 70 basement water samples from Hole 504B. The $\mathrm{Si} / \mathrm{Ca}$ ratio in the samples increases with increasing sub-basement depth and temperature. Shaded area denotes the estimated uncertainty in the extrapolation from samples PS-2 to PS-5, which were collected at $212 \mathrm{~m}$ sub-basement depth.

experiments quantitatively to the in situ experiment inadvertently performed in Hole 504B. Although the surface area of the powdered basalts used in the experiments was high, the water-to-rock ratio was also high. The implication of the results from Hole 504B is that the. ratio of reactive surface area of the rock to mass of interstitial solution was higher in the crust than in the experiments.

One way to estimate the composition of the true basement formation waters at Sites 501 and 504 is suggested by the composition of the sediment pore waters. Mottl et al. (this volume) showed that there are large and systematic lateral gradients in $\mathrm{Ca}, \mathrm{Mg}$, alkalinity, and other chemical species in the sediment pore water over the 500-meter east-west distance covered by the five holes at these sites. These gradients may result from similar gradients in the underlying basement formation water. In Figures 2 to 5 , the mixing lines defined by the packer aliquots pass through or near the point for the lowest sedi- ment pore water sample (from $10 \mathrm{~m}$ above basement) in Hole 504B. This relationship is further illustrated in Figure 7, which shows all of the pore water data from Legs 68 (Site 501) and 69 for $\mathrm{Ca}$ and $\mathrm{Mg}$ from both sediments and basement. The mixing line for the Leg 69 packer samples generally defines a different relationship for $\mathrm{Ca}$ versus $\mathrm{Mg}$ than the sediment pore waters. The notable exceptions among the sediment pore waters are the three deepest samples, one each from Holes 501, 504A, and 504B. These are the only three samples that were taken from below the diagenetic boundary between chalk above and chert plus limestone below.

The fact that the deepest sediment pore waters at different geographical locations vary in $\mathrm{Ca}$ and $\mathrm{Mg}$ content yet retain the same relationship between $\mathrm{Ca}$ and $\mathrm{Mg}$ as the reacted seawater sampled from basement suggests that the basal sediment pore waters may well resemble the true formation water. The formation water may even control the composition of the basal sediment pore water with respect to $\mathrm{Ca}$ and $\mathrm{Mg}$ concentration. This hypothesis is highly tentative, however, because the extent to which the samples resemble true basement formation water is unclear. Furthermore, it cannot be determined whether the reacted seawater sampled from the basement in Hole 504B has equilibrated at the high $\mathrm{Mg}$ and low $\mathrm{Ca}$ concentrations of the basal sediment pore water or whether it is simply changing composition via the same $\mathrm{Ca}$ versus $\mathrm{Mg}$ relationship and so is moving along the same mixing line.

In either case, there is no requirement for the quantities of other chemical species in the formation water to have the same ratio to $\mathrm{Ca}$ as in the basal sediment pore waters, although alkalinity, chlorinity, and possibly $\mathrm{Si}$ do (Figs. 3, 4, and 6). One reason is that for some species the influence of the chemistry of the basement formation water may be overwhelmed by reactions with the basal sediments. Another is that if the surface seawater is still changing composition due to reaction with basalt, the rate of change of the concentration of a given chemical species relative to that of Ca may vary with time, unless the relationship is fixed by coupled reaction or charge balance constraints. Thus, even the similarity between the basement water and basal sediment pore water ratios may be spurious. Chemicals that yield mixing lines when plotted against $\mathrm{Ca}$ that pass through surface seawater but not through the basal sediment pore water composition for Hole 504B are $\mathrm{Sr},{ }^{87} \mathrm{Sr} /{ }^{86} \mathrm{Sr}$, and probably $\mathrm{K}$, all of which decrease with increasing $\mathrm{Ca}$ as the fraction of reacted interstitial solution in the samples increases (Hart and Mottl, this volume).

Three of the chemicals analyzed here $(\mathrm{Fe}, \mathrm{Mn}$, and Li) yielded values uniformly higher than in surface seawater, with some degree of scatter. The high and variable concentrations are almost certainly due to contamination from the steel sampler barrels for $\mathrm{Fe}$ and $\mathrm{Mn}$ and from the greases used on the moving parts of the sampler for $\mathrm{Li}$.

\section{CONCLUSION}

Although the first attempts to sample basement formation waters did not succeed, they yielded useful in- 


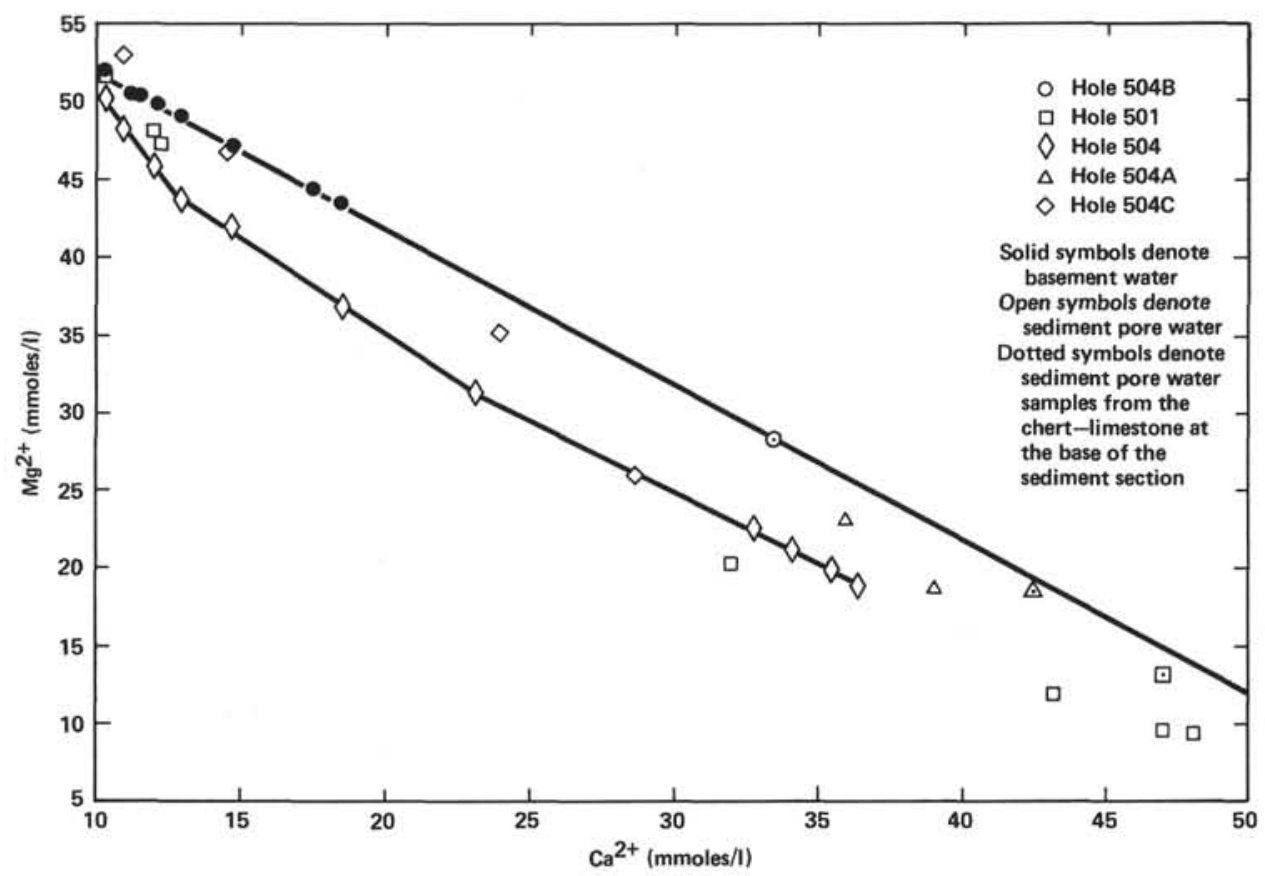

Figure 7. Ca versus $\mathrm{Mg}$ in the Leg 69 Hole 504B basement water samples and in the sediment pore water from Holes 501, 504, 504A, 504B, and 504C. The basement water samples and the three sediment pore water samples from the chert-limestone at the base of the sediment section (dotted) define a linear relationship that is distinct from that of nearly all the other sediment pore water samples.

formation on the rate and direction of reaction between basalt and seawater in the oceanic crust at moderate temperatures. The packer sampler is clearly capable of drawing interstitial water from basaltic basement. The passive sampling of the water that occupied the drill hole also produced water that showed large chemical changes from seawater. Closer attention to the sequence of drilling and experimental operations should permit the collection of samples that contain a large fraction of true formation water in the future.

\section{APPENDIX \\ Sampling Operations}

\section{Hole 501}

The packer sample was taken before basement drilling was complete, with the packer set 3 meters above what was then the bottom of the hole. The rubber packing element had been damaged during drilling, as indicated by the recovery of rubber in two of the basement cores, so some water was able to pass downward through the hole and across the imperfect seal when the sampler was opened. Only one check valve was used, segregating the last 8.51 of the 51 collected into a separate aliquot (P-9). An attempt to label the drilling fluid (surface seawater) with $\mathrm{NH}_{4} \mathrm{Cl}$ failed because the spiked seawater was pumped down in too small a quantity and too slowly to reach the bottom of the hole before the sample was taken.

The G-O sample was taken in conjunction with the second temperature log about $52 \mathrm{hr}$. after drilling had stopped and $48 \mathrm{hr}$. after pumping for the packer flow tests had stopped. The sample was taken about 25 meters above the bottom of the hole, which was estimated to be filled to about that depth with soft sediment which had fallen down the hole. The sampler proved to be defective, collapsing almost completely under the pressure of $\leq 380$ bars within the hole. The sampling port had opened but had failed to close again because of clogging by sand. A very small, muddy sample was obtained.

Both samplers used in Hole 501 were sent down filled with air.

\section{Hole 504B: Leg 69}

The G-O sample was taken along with the second temperature log $70 \mathrm{hr}$. after the circulation of drilling fluid (surface seawater) had stopped and 20 meters above the bottom of the hole. The sampling port failed to close at first, and closure could not be confirmed until the tool had been hauled 62 meters higher. A coupling was loose and leaking when the tool arrived on deck, but the sampler yielded 2.21 of cloudy, bright-rust-colored water (the sampler's total volume is $\mathbf{2 . 6 5}$ 1). A steel filter screen mounted over the sampling ports kept the sample nearly free of sediment. Iron hydroxides, which could be removed with a $0.45 \mu \mathrm{m}$ filter, continued to precipitate for several hours. Within 24 hours all precipitate had settled. The high iron concentration almost certainly resulted from the reaction of the $69^{\circ} \mathrm{C}$ (as collected) water with the sample chamber, a steel pipe. The sampler was sent down filled with $1 \mathrm{~atm}$. of nitrogen gas.

The packer sample was taken after the logging operations were complete. The bit was set on the bottom of the hole and the hole was flushed first with $2100 \mathrm{gal}$. (50 bbl.) of barite-bentonite freshwater mud and then with about 6000 gal. of surface seawater, roughly equal to the volume of the hole. The packer was set firmly with the sampling port 3 meters above the bottom of the hole. Upon opening the sampler, an in situ pressure drop of 310 bars occurred because the pressure regulator valve designed to limit the differential pressure across the rubber packer element failed to operate properly. This tore the element loose and pulled it downward on the pipe, but the element maintained a good seal as the sample was taken. Five days before this sampling episode, the packer had been set in exactly the same place to make pressure-pulse permeability measurements (see Anderson and Zoback, this volume), and 1000 gal. of surface seawater had been pumped into the formation over the same 3-meter interval at the bottom of the hole.

The packer sampler was sent down with the lowest barrel isolated via a one-way valve. A second valve located two barrels higher failed to seat properly after sampling. The upper three barrels were evacuated through a needle valve located above the uppermost barrel. The sampler arrived on deck at a measured pressure of 155 bars, versus about 400 bars in situ. Three hundred ml of mostly water were bled 
from the top of the sampler into a steel cylinder, causing a pressure drop to 34 bars. A second cylinder of $500 \mathrm{ml}$ volume was filled with about $10 \%$ seawater and $90 \%$ gas, bringing the pressure slightly above atmospheric. The main water sample was cloudy gray because of suspended powdered basalt and (unlike the G-O sample) showed no tendency to precipitate iron hydroxides. Aliquot PS-1 (8.51) was removed from the lowest barrel, PS-A $(0.5 \mathrm{l})$ came from the sleeve beneath that barrel, and PS-S (12 ml, muddy) was removed the following day from the sampling port assembly. Each of these aliquots had been isolated from the others within the sampler. Aliquots PS-2 through PS-5 were 10- to 12-1 volumes that were emptied successively from the upper five barrels of the sampler, from below, in reverse order of filling: thus, PS-5 represents the first water in and the last out. Although these aliquots were not isolated from one another within the sampler, sampler geometry maintained the original compositional stratification of the sample.

\section{Hole 504B: Leg 70}

Four samples were collected with the Barnes in situ sampler. When the timer-operated valve of this tool opens, water flows under hydrostatic pressure through a stainless steel filter screen into two coils of metal tubing arranged in series, displacing the distilled water that initially occupied the copper and stainless steel coils into an overflow cylinder initially filled with air. The overflow cylinder has a pressure relief valve. When a full sample is taken, the prime aliquot in the stainless steel coil is normally undiluted, whereas the aliquot from the overflow cylinder is diluted to varying degrees with distilled water displaced from the coils (Table 2).

Barnes samples IW-173 and -714 were taken on reentering Hole 504B 39 days after pumping through the hole on Leg 69 had ceased and before renewed drilling on Leg 70. Samples IW-175 and -194 were taken near the bottom of the hole immediately after the second and third re-entries, respectively, about 1 day after drilling had stopped.

The G-O sample was taken 1 meter above the bottom of the hole 4 days after the pumping of drilling fluid had stopped. The sampler ruptured a filter screen and came up filled with 11 of wet drilling mud and basalt chips.

\section{Hole 505B}

A G-O sample was taken on the second temperature logging run, $48 \mathrm{hr}$. after the hole was drilled and flushed with 2100 gal. of baritebentonite freshwater mud and a volume of surface seawater 2.5 times the volume of the hole. The tool may have lodged in the hole 8 meters into basement, although nominally the sample is from 23 meters into basement, 19 meters above the bottom of the hole. One of the screens covering the sampling ports clogged with sediment and imploded, so that only $140 \mathrm{ml}$ of muddy water entered the sampler during the 5 to $10 \mathrm{~min}$. the valve was open. This sample was centrifuged before being filtered.

\section{ACKNOWLEDGMENTS}

We wish to thank our colleagues Geoff Thompson and Fred Sayles for critically reviewing the manuscript. This work was supported by National Science Foundation grants OCE 80-19056 (to MJM) and OCE 77-24819 and OCE 80-24044 (to JRL). This is WHOI contribution number 5024 .

\section{REFERENCES}

Anderson, R. N., Langseth, M. G., and Sclater, J. G., 1977. The mechanisms of heat transfer through the floor of the Indian Ocean. J. Geophys. Res., 82:3391-3409.

Edmond, J. R., Von Damm, K., McDuff, R. E., and Measures, C. I. 1982. Chemistry of hot springs on the East Pacific Rise and their effluent dispersal. Nature. 297:187-191.

Gieskes, J. M., 1974. Interstitial water studies, Leg 25. In Simpson, E. S. W., Schlich, R., et al., Init. Repts. DSDP, 25: Washington (U.S. Govt. Printing Office), 361-394.

Lawrence, J. R., Gieskes, J. M., and Broecker, W. S., 1975. Oxygen isotope and cation composition of DSDP pore waters and the alteration of Layer II basalts. Earth Planet. Sci. Lett., 27:1-10.

Lister, C. R. B., 1980. Heat flow and hydrothermal circulation. Ann. Rev. Earth Planet. Sci., 8:95-117.

Lonsdale, P., and Klitgord, K. D., 1978. Structure and tectonic history of the eastern Panama Basin. Geol. Soc. Am. Bull., 89:981-999.

Mottl, M. J., and Holland, H. D., 1978. Chemical exchange during hydrothermal alteration of basalt by seawater-I. Experimental results for major and minor components of seawater. Geochim. Cosmochim. Acta, 42:1103-1115.

Sayles, F. L., and Mangelsdorf, P. C., Jr., 1976. The analysis of $\mathrm{SO}_{4}^{2-}$ in seawater by difference chromatography. Limnol. Oceanogr., 21: 899-905.

Seyfried, W. E., Jr., 1977. Seawater-basalt interaction from $25^{\circ}-$ $300^{\circ} \mathrm{C}$ and 1500 bars: implications for the origin of submarine metalbearing hydrothermal solutions and regulation of ocean chemistry [Ph.D. dissert.]. Univ. So. Calif.

Seyfried, W. E., Jr., and Bischoff, J. L., 1979. Low temperature basalt alteration by seawater: an experimental study at $70^{\circ} \mathrm{C}$ and $150^{\circ} \mathrm{C}$. Geochim. Cosmochim. Acta, 43:1937-1947. 